\title{
Bathymetric and Geochemical Analysis of Lake Al-Saad, Abha, Kingdom of Saudi Arabia Using Geoinformatics Technology
}

\author{
Javed Mallick ${ }^{*}$, Mohd Abul Hasan', Yasser Alashker1,2, Mohd Ahmed ${ }^{1}$ \\ ${ }^{1}$ Faculty of Engineering, King Khalid University, Abha, Kingdom of Saudi Arabia \\ ${ }^{2}$ Faculty of Engineering, Zagazig University, Zagazig, Egypt \\ Email: javnaffi@gmail.com
}

Received 23 July 2014; revised 20 August 2014; accepted 15 September 2014

Copyright (C) 2014 by authors and Scientific Research Publishing Inc.

This work is licensed under the Creative Commons Attribution International License (CC BY).

http://creativecommons.org/licenses/by/4.0/

c) (i) Dpen Access

\section{Abstract}

This study investigates the potential for remote sensing of lake water bathymetry and geochemical by 1) examining the empirical based technique for retrieving depth information from passive optical image worldview-2 satellite data, 2) performing atmospheric correction, 3) assessing the accuracy of spectrally based depth retrieval under field condition via field measurement, 4) producing bathometry and geochemistry mapping by examining spectral variations for identifying pairs of wavelengths that produce strong linear correlation coefficient between the band ratio. The results indicate that optical remote sensing of bathymetry and geochemical investigation is not only feasible but more accurate under conditions of typical lake water, supporting field survey. The Pearson correlation matrix $(\mathrm{R})$ between the examined water samples/depth and the TOA reflectance values of the worldview-2 (WV-2) satellite data have been investigated and found good correlation. The models developed using the combination of different band pairs also show high accuracy. Cartographical maps were generated depending on the linear correlation coefficient between the measured parameters and the TOA reflectance values of the worldview- 2 data. The investigation shows that dissolved oxygen (DO) of the lake water is slight lower than the permissible limit of Saudi standards for lake water. The shallow water has high Do concentration, whereas the deeper shows significantly lower down. Electrical conductivity measurements serve as a useful indicator of the degree of mineralization in the water sample. All the samples which have EC exceed limit. The spatial distribution of EC and TDS inferred that the EC and TDS concentration is the highest at the eastern part of the lake whereas concentration drops down towards the southern side. This study confirms that remote sensing incorporated with GIS and GPS could

\footnotetext{
"Corresponding author.
} 
afford an integrated scheme for mapping water quality and bathometry of the surface water.

Keywords

Geochemical Water Properties, Bathymetry, Worldview-2 Data, Remote Sensing and GIS

\section{Introduction}

Lakes and reservoirs bathymetry mapping have important value in hydrological studies. Besides water level volume or lake area or stage curve relationships, multi-temporal comparisons between bathymetries is an indicator for the environmental assessment such as sedimentation, biodiversity and sustain activities such as agriculture, fisheries and recreation. Conventional approaches to bathymetric mapping depend upon extensive field surveys of water depths at sampled locations. However, such approaches are characterized as being labor-intensive and time consuming [1]. Also, it is often difficult to accomplish the desired continuous spatial mapping accuracy due to the limited number of sampled points. On the other hand, state-of-art mapping approaches include boat/ship borne underwater dragging sonar to record returned sounding signals in a fixed time interval for extensive water depth measurements [2]. Such advanced approach can accurately measure the underwater topography but its high cost makes it less accessible for generic low-budget research projects.

Ever since the 1970s, satellite based remote sensing technology and geographical information system (GIS) has been adopted as an alternative to minimize field work for bathymetry and geochemical mapping (e.g. [3][8]). With the Remote Sensing (RS), Global Positioning System (GPS) and Geographical Information System (GIS) technology advancement and maturing, it has been applied to many fields [9] [10]. One of applications of RS technology is to indirectly measure water depth. This indirect method uses space based satellite sensors to receive the sunlight's reflection and emission-thermal radiation of a water body. Consequently, the satellite data are processed to retrieve water depth. The available retrieval models can be classified into theoretical, empirical (statistical) correlation [11].

The theoretical model is based on the transmission equation (by measuring optical parameters) of electromagnetic radiation in water. This model has not been widely used in practice because the optical parameters relevant to water body and required by those models cannot be determined and because the timings of other measureable parameters may not be coincident with those of satellite data. Lyzenga [12] simplified the classical irradiation equation by neglecting the radiometric effects of water body and obtained the relationship between water-leaving radiant energy and water depth. However, this model requires a complex estimation for a number of water column parameters, some of which can be very difficult to obtain; thus it is not widely used in practical water depth mapping [11]. Empirical model integrates the merits of both theoretical and statistical. It is based on the statistical relationship through the use of statistical regression to estimate the photochemical parameters. This model includes bottom-albedo based mono spectral band models and multispectral band ratio models [11]. The mono spectral band model assumes an ideal situation with vertical homogeneity for water body's photochemistry, high and invariable bottom albedo, and shallow water [13]. These geographical phenomena were rarely found in reality and laid an important framework for further development. The multispectral band ratio model, under the assumption of no variability of vertical homogeneity for water body's photochemistry, bottom albedo in relation to bottom composition, Brown [14] achieved good accuracy of bathymetry mapping by taking the ratio between two spectral bands to reduce the bottom effects. By considering water quality and atmospheric conditions constant, Philpot [4] discussed the effects of augmenting the number of influencing factors for bathymetry mapping. The results showed that spectral analysis alone become increasingly unreliable when increasing the level of model complexity, unless ancillary data such as spatiotemporal image can be also used. The most significant progress in this research orientation was done by two individuals [6] in their effects to minimize the use of in-situ data for light attenuation coefficients in water column. This study considers three practical issues (depth modelling, atmospheric condition and bottom albedo) in lake water mapping. The study area was Lake Al-Saad, Saudi Arabia. The worldview-2 satellite image was acquired on $15^{\text {th }}$ October 2013 coinciding with the field surveying for water sample and depth. The objective of this study was to assess the bathymetry and geochemical mapping of Lake Al-Saad, Saudi Arabia based on the statistical regression using multispectral band ratio. 


\section{Study Area}

A case study area has been selected demonstrate the concept of lake bathymetry by the 3S (remote sensing, Geographical Information system (GIS) and Global Position System) technology. The Lake Al-Saad has chosen for the study is situated in Abha, Aseer province of kingdom of Saudi Arabia (Figure 1). The boundary of the study arealies between the latitude of $18^{\circ} 12^{\prime} 29.355^{\prime \prime} \mathrm{N}$ and $18^{\circ} 12^{\prime} 51.436^{\prime \prime} \mathrm{N}$ and longitude of $42^{\circ} 29^{\prime} 5.157^{\prime \prime} \mathrm{E}$ and $42^{\circ} 29^{\prime} 19.795 " \mathrm{E}$ and surface elevation from the mean sea level is 2282 meters. It covers an area of 6.87 hectares and having sedimentary soft, hard silt and clay rocks surround the lake [15]. The climatic condition in the surrounding study area is semi-arid. The average annual rainfall of $355 \mathrm{~mm}$ with the bulk of the rainfall is occurring between June and October and average minimum and maximum temperatures of $19.3^{\circ} \mathrm{C}$ and $29.70^{\circ} \mathrm{C}$, respectively. It plays an important role especially in the local eco-sustainability and social values.

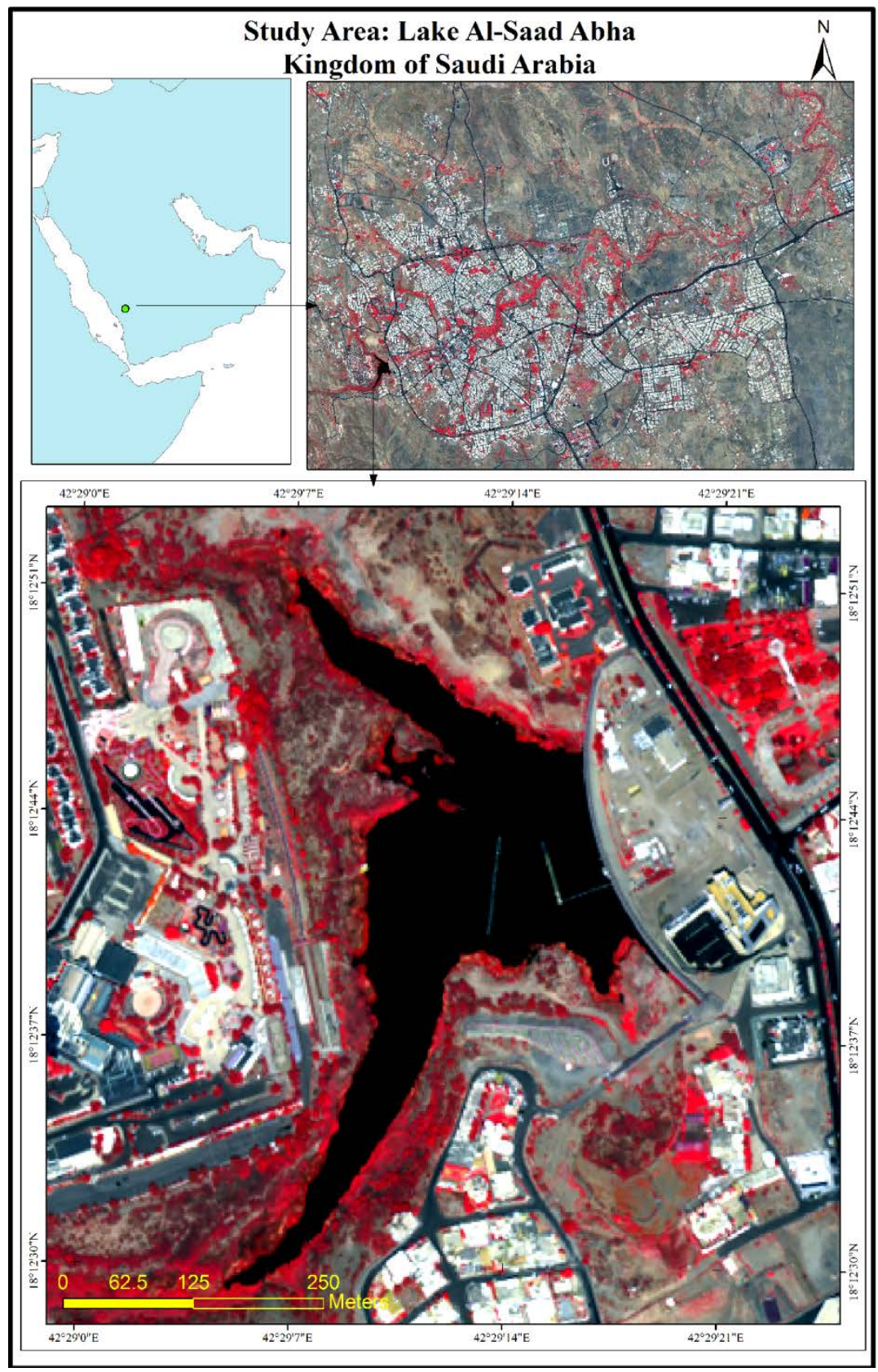

Figure 1. Study area. 


\section{Data and Methods Used}

Worldview-2 (WV-2) satellite dataset is used in this study for understanding the surrounding geographic phenomenon environment, and bathymetry mapping. WV-2 is digital globe's second next-generation satellite, built by ball aerospace, and leveraging the most advance technologies. WV-2 satellite data having very high spatial land spectral resolution of $50 \mathrm{~cm}$ (pan); 1.84 meter 8-band multi-spectral imagery. The high spectral resolution provides detailed information on diverse areas as the quality of build-up surface, health of vegetation and depth of water bodies and its biophysical properties. The worldview-2 satellite data was acquired from the Digital Globe via a file transfer protocol (FTP) as bundle (panchromatic +8 bands multi-spectral). The data product is stored in GeoTIFF file format and has 16 bit radiometric resolution. Orthorectification of the satellite imagery was undertaken using the sensor's rational polynomial coefficient (RPC) and ground control points. Digital elevation model (DEM) was created, using 20 meter contour from topographical map acquired from surveying department, the Kingdom of Saudi Arabia. DEM was used in the Orthorectification process. Coordinates for 13 Ground Control Points (GCPs) distributed evenly across the imagery were acquired using DGPS (the overall position accuracy was $9.82 \mathrm{~mm}$ ). Eight GCPs were used in the Orthorectification of image. The overall accuracy assessment of the Orthorectification based on 5 independent GCPs was evaluated. The overall RMSE of $1.89 \mathrm{~m}$.

\subsection{Conversion of Raw DNs to Spectral Radiance at the Sensor}

To account for sensor characteristics, the satellite image was converted from DN to $L_{\lambda}$ spectral radiance using Equation (1) [16]:

$$
L_{\lambda \text { Pixe,Band }}=\frac{K_{\text {Band }} \times Q_{\text {Pixe,Band }}}{\Delta_{\lambda \text { Band }}}
$$

where, $L_{\lambda \text { Pixe,Band }}$ is the TOA (top-of-atmosphere) spectral radiance image pixel $\left(\mathrm{W} \cdot \mathrm{m}^{-2} \cdot \mathrm{sr}^{-1} \cdot \mu \mathrm{m}^{-1}\right) ; K_{\mathrm{Band}}$ is the absolute radiometric calibration factor $\left(\mathrm{W} \cdot \mathrm{m}^{-2} \cdot \mathrm{sr}^{-1} \cdot \operatorname{count}^{-1}\right)$ for a given band; $Q_{\text {Pixel,Band }}$ represents the radiometrically corrected image pixels (DN); $\Delta_{\lambda \text { Band }}$ is the effective bandwidth $(\mu \mathrm{m})$ for a given band; The absolute calibration $\left(K_{\text {Band }}\right)$ and effective bandwidth $\left(\Delta_{\lambda \text { Band }}\right)$ parameters for each band are obtained from the metadata supplied with the imagery.

\subsection{Conversion of Spectral Radiance to TOA Reflectance $\left(\rho_{\lambda}\right)$}

Top of the atmosphere (TOA) reflectance recorded at the sensor is obtained by converting the radiance $\left(L_{\lambda \text { Pixe,Band }}\right)$ recorded at the sensor to reflectance $\left(\rho_{\lambda}\right)$ using the Equation (2) [16].

$$
\rho_{\lambda \text { Pixe,Band }}=\frac{L_{\lambda \text { Pixe,Band }} \times d_{E S}^{2} \times \pi}{E_{\text {sun }_{\lambda \text { Band }}} \times \cos \left(\theta_{s}\right)}
$$

where, $\rho_{\lambda \text { Pixe,Band }}=$ Planetary TOA reflectance; $L_{\lambda \text { Pixe,Band }}=$ Spectral radiance image pixel $\left(\mathrm{W} \cdot \mathrm{m}^{-2} \cdot \mathrm{sr}^{-1} \cdot \mu \mathrm{m}^{-1}\right) ; d$ $=$ Earth-Sun distance (astronomical units); $E_{\text {sun }_{\lambda \text { Band }}}=$ Mean exoatmospheric solar irradiance $\left(\mathrm{W} / \mathrm{m}^{2} \cdot \mu \mathrm{m}\right) ; \theta_{s}=$ Solar zenith angle (degree); $\pi=$ Mathematical constant (3.14159).

\subsection{Atmospheric Correction of Worlview-2 Satellite Imagery Data}

The effective assessment of any meaningful qualitative and quantitative information from the satellite image, the sensing signal recorded at the sensor needs to be corrected for atmospheric effects, in order to allow the retrieval of pure surface radiances from the target. This is due to the radiance recorded at the sensor is from different sources in addition to the water leaving reflectance. The proportion of radiance reflected from water column is very small, usually less than $20 \%$ of total signal [17], and therefore accurate radiometric correction is important for the assessment of water quality. The total radiance received at the sensor (TOA) can be divided into several components as Equation (3):

$$
L_{\lambda T O A}=L_{\lambda \mathrm{Pixe}, \text { Band }}+L_{\lambda \text { ars }}+\tau_{\lambda r} \times\left(L_{\lambda s f c}+L_{\lambda w}\right)
$$

where, $L_{\lambda \text { Pixe,Band }}$ is radiance resulting from scattering by air molecules (Rayleigh scattering) in the absence of aerosol, $L_{\lambda \text { ars }}$ is the contribution from aerosol scattering in the absence of air, $L_{\lambda s f c}$ is the contribution from 
the surface, $\tau_{\lambda r}$ is the viewing diffuse transmittance of the atmosphere and $L_{\lambda w}$ is the desired water leaving radiance.

It follows therefore, by conversion of spectral radiance to reflectance; the total reflection $\rho_{t \lambda \text { PixeBand }}$ recorded at the sensor can be divided into following components:

$$
\rho_{\mathrm{t} \lambda}=\rho_{\mathrm{r} \lambda \mathrm{Pixe}, \mathrm{Band}}+\rho_{\lambda \text { ars }}+\tau_{\lambda r}
$$

where, the subscripts of the reflectance represent the contribution from air molecules $r$, aerosol ars; $L_{\lambda s f c}$ and $L_{\lambda w}$ are considered very small and is henceforth dropped (for surface, low wind speeds assumed).

\section{Rayleigh reflectance estimation}

In terms of geometry and atmospheric pressure [18], the contribution of Rayleigh scattering to the total reflectance can accurately be obtained by Equation (5)

$$
\rho_{r}(\lambda)=\frac{t_{o z} \times \tau_{r} \times p r}{4 \cos (\theta o) \times \cos (\theta v)}
$$

where, $p_{r}$ is the Rayleigh scattering phase function. The Rayleigh (molecular) scattering phase function is obtained from its relationship with the scattering angle which is described Equation (6)

$$
p_{r}=0.75\left(1+\cos ^{2} \Psi\right)
$$

where, $\Psi$ is the light scattering angle. From sensor viewing and illumination geometry, this angle is described by [19] Equation (7)

$$
\cos \Psi=\cos \theta o \times \cos \theta v+\sin \theta o \times \sin \theta v \times \cos (\Phi o-\Phi v)
$$

where, $\theta o, \theta v$ are sun zenith and satellite viewing angles and $\Phi o, \Phi v$ the sun and satellite azimuth angles in radians, respectively. $\tau_{r}$ is Rayleigh optical thickness, calculated using Equation (8) [20]

$$
\tau_{r}(\lambda, z)=0.008569 \lambda^{-4}\left(1+0.0113 \lambda^{-2}+0.00013 \lambda^{-4}\right) \frac{P(z)}{P(0)}
$$

where, $\lambda$ is wavelength in $\mu \mathrm{m}$ and $P(0)=1013.25 \mathrm{mb}$ is standard atmospheric pressure at sea level. $z$ altitude (in the study area $=2200 \mathrm{~m}) . P(z)$ is atmospheric pressure at altitude $z$ i.e. $770 \mathrm{mb}$ in this study $t_{o z}$ is two way ozone atmospheric transmittance described by Voillier et al. [21] as Equation (9)

$$
t_{o z}=\exp \left(-k(\lambda) U\left(\cos ^{-1}(\theta o)+\cos ^{-1}(\theta v)\right)\right)
$$

where, $k(\lambda)$ is the Ozone absorption coefficient from [22] and $U$ is the ozone total column content in atm-cm (in studied area: $0.266 \mathrm{~atm}-\mathrm{cm}$ ), obtained from http://ozoneaq.gsfc.nasa.gov.

\subsection{Field Survey for Bathymetry and Hydrochemistry of Water}

Water sample were collected from various spatial locations in the Lake Al-Saad. A total of 46 water samples and bathymetry surveys were carried out on $15^{\text {th }}$ October, 2013 in polypropylene bottles immersed $20-30 \mathrm{~cm}$ below the water surface. 1) At each site, field measurements were carried out including the geographic location using a differential global positioning system (DGPS Leica GPS1200); 2) The water quality parameters such as DO, pH, total dissolved solid (TDS) and electrical conductivity (EC) were measured onsite using respective portable electrodes; 3) Water depth using manual staff gage (as the maximum depth 6 meter in the study site).

\subsection{Statistical and Spatial Analysis of Water Sample}

Statistical parameters (mean, median, minimum, maximum, standard derivation, Skewness, kurtosis and the coefficient of variation were computed for each water quality parameter by the software package SPSS. The statistical data analysis included a Pearson correlation analysis. Prior to the geo-statistical data analysis, the data were tested for normality using K-S (Kolmogorov-Smirnov) test for goodness of fit [23]. Geo-statistical analysis comprise a group of spatial statistical techniques that evaluate the autocorrelation commonly observed in geospatial data, where the data values from locations close to each other are more symmetry than the data values from locations far apart. 
Spatial interpolation technique is commonly used to generate continuous information (raster based) when the point data information is available at several sampling locations (water quality parameters). Ordinary Kriging (OK) model is one of the interpolation techniques, which weighs the surrounding known values to derive estimations for an unmeasured location. Though, the weights are based not only on the distance between the known values and unknown values but also on the overall geostatistical relationships among the known values. OK method is based on the creation of a semi-variogram and from the information contained in the best fitted model of the semi-variogram the interpolation values are determined. The semi-variogram is a plot between the distance of ordered data and their value of semivariance, this plot explains the spatial relation between the water analyzed values, and is given by the following Equation (10)

$$
\gamma(h)=\frac{1}{2} N_{(h)} \sum\left[Z_{i}-Z_{i+h}\right]^{2}
$$

The most related samples have lower values of semivariance $(\gamma(h)) . N_{(h)}$ is the number of water quality parameter values that can be grouped using vector $h ; Z_{i}$ is the value of the water parameters; $Z_{i+h}$ represents the value of another sample located at a distance " $h$ " from the initial sample $Z_{i}$. The semi-variogram is a point graphic with points plotted at specific distance interval, since there is the need to know semivariance value at distances not defined in the plot, a model was fitted using the lowest possible root square error (RSE) [24]. The "best fit" model provides two important parameters nugget and sill to determine whether the samples are spatially correlated or not. If the ratio between nugget and sill is low i.e. $<0.25$ then the samples are spatially correlated, contrary if the ratio is high i.e. $>0.75$ then the samples have a very low spatial correlation [25]. This parameter indicates the spatial structure of the phenomenon and samples with a high spatially relationship will show better interpolation results. Prior to creating continuous surface, the distribution of the different water quality properties is analyzed to better understand the trends, which influences directional and obvious errors. Transformation and trend removal was performed when necessary. Kriging cross-validation was used to estimate that of the semi-variogram models could give the most accurate predictions at unknown locations. The closer the mean error was to zero, the closer the root-mean-square standardized error was to 1 , signified that the prediction values were close to measured values (Castrignano et al., 2007). Where models presented similar values for mean error and root-mean-square error, the lowest values of root-mean-square error and average standard error were taken into consideration.

\section{Result and Discussion}

\subsection{Hydro-Geochemistry of Lake Water}

The $\mathrm{pH}$ value for the lake water ranges from 7.7 to 8.1 (Figure 2). A desirable range of $\mathrm{pH}$ for aquatic life is 6.5 to 9.0 [26]. $\mathrm{pH}$ above or below this threshold value might interfere with reproduction, respiration and other biological functions of aquatic life. Although the tolerance of individual species varies, $\mathrm{pH}$ values between 6.5 and 8.5 usually indicate good water quality and this range is typical of most major drainage basins of the world [27]. The ability of rocks and soils in any given drainage basin to buffer the acidity of rainwater is related to the residence time of water in the soil as well as the levels of calcium carbonate, bicarbonate, and silicate minerals [28]. Watersheds with soil rich in calcium carbonate will provide buffering to lakes, which otherwise with low buffering capacity would be susceptible to acid deposition or acid runoff. The summary of of physical and chemical parameters of Lake Al-Saad is showed in Table 1. Dissolved oxygen (DO) of the lake water was in the range of $4.38-6.73 \mathrm{mg} / \mathrm{L}$ with the mean of $5.38 \mathrm{mg} / \mathrm{L}$ (Figure 2). The available data indicated that Lake Al-Saad water is slight lower than the permissible limit of Saudi standards for lake water $(10 \mathrm{mg} / \mathrm{L})$. The DO in an aquatic ecosystem is responsible for various biochemical changes and subsequently its effect on metabolic activities of organisms within the lake ecosystem. In a nutrient-rich water body, the DO is quite high in the surface water due to increased photosynthesis by the large quantities of algae. However, DO tends to decrease in deeper waters because photosynthesis is reduced due to poor light penetration and due to the fact that dead algae falls towards the bottom using up the oxygen as it decompose. In the study area it is found that the shallow water has high DO concentration, whereas deeper shows significantly lower down. DO is the single most important gas for most aquatic organisms. When the aquatic organisms exposure to less than $2.0 \mathrm{mg} / \mathrm{L}$ free oxygen for few days it may kill most of biota in the aquatic system [29], while values of $5.0-6.0 \mathrm{mg} / \mathrm{L}$ are usually for most of fish population. The DO trend in Al-Saad lake is not very encouraging as majority of the lake area is under DO stress or 

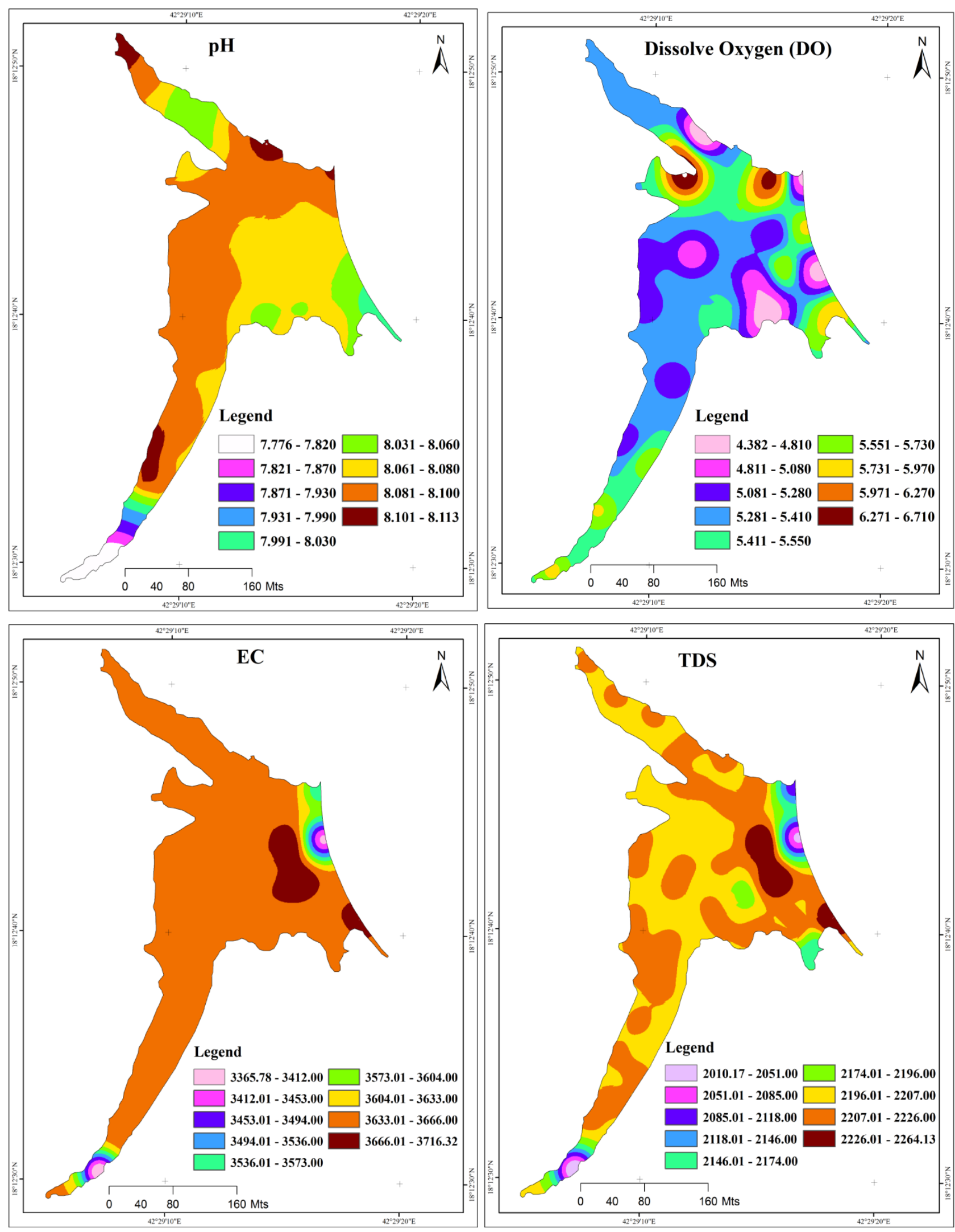

Figure 2. Spatial distribution of $\mathrm{pH}, \mathrm{DO}, \mathrm{EC}$ and conductivity of Lake Al-Saad, Abha. 
Table 1. Summary of physical and chemical parameters of Lake Al-Saad.

\begin{tabular}{ccccc}
\hline Sample No & EC & TDS & pH & DO \\
\hline Minimum & 3366.00 & 2010.00 & 7.76 & 4.38 \\
Maximum & 3710.00 & 2260.00 & 8.12 & 6.73 \\
Mean & 3637.80 & 2198.64 & 8.06 & 5.38 \\
Std. dev & 62.45 & 46.98 & 0.07 & 0.56 \\
Skewness & -3.37 & -2.71 & -3.41 & 0.26 \\
Kurtosis & 12.35 & 8.20 & 12.90 & -0.28 \\
\hline
\end{tabular}

Nate: Concentrations are in mg/L, except for EC $(\mu \mathrm{S} / \mathrm{cm})$ and $\mathrm{pH}$.

marginally above it. So a proper management strategies need to be formulated to protect flora and fauna of the lake. Conductivity measurements serve as a useful indicator of the degree of mineralization in the water sample. All the samples which have EC exceeded limit and it ranges from $3366 \mu \mathrm{s} / \mathrm{cm}$ to $3710 \mu \mathrm{s} / \mathrm{cm}$ with the mean value of $3637.79 \mu \mathrm{s} / \mathrm{cm}$. EC of most natural water generally ranges about 50 to $1500 \mu \mathrm{s} / \mathrm{cm}$. In general, with increase of EC, the corrosive nature of the water increases. Figure 2 shows the spatial distribution of EC and TDS, it inferred that the EC and TDS concentration is the highest at the eastern part of the lake whereas concentration drops down towards the southern side.

\subsection{Correlation Analysis between Examined Water Sample and the Satellite Value}

The Pearson correlation matrix (R) between the examined water samples and the TOA reflectance values of the WV-2 satellite data is presented in Table 2. The water depth, EC, TDS, and DO are correlated with the reflectance values of the WV-2 satellite image. Electrical conductivity is highly negative correlated with Band $2(\mathrm{R}=$ -0.668) whereas with Band $6(\mathrm{R}=-0.445)$ and Band $7(\mathrm{R}=-0.455)$ it shows moderate negative correlation. Dissolved oxygen (DO) is having highly negative correlation with Band 4/Band 8, Band 6/Band 8 and WVIND4 of $\mathrm{R}$ value $-0.602,-0.571$ and -0.579 respectively at the significant level $\mathrm{P}<0.001$ (2-tailed). Water depth is highly correlated with Band 1/Band $4(\mathrm{R}=0.848)$, Band $4(\mathrm{R}=-0.780)$, Band 1/Band $5(\mathrm{R}=0.715)$ and Band $1 /$ Band $6(\mathrm{R}=0.702)$ at the significant level $\mathrm{P}<0.001$ (2-tailed). The models representing the statistical relationships for the examined water parameters and the TOA reflectance value of the WV-2 satellite image as shown as below. Figure 3 shows the graphical representation of linear correlation coefficient between examined parameters with model estimated values.

Electrical conductivity (EC) model

$$
\mathrm{EC}_{\mu \mathrm{s} / \mathrm{cm}}=a+(X 1 \times b)+(X 2 \times c)+(X 3 \times d)
$$

where EC is expressed in $\mu \mathrm{S} /$ centimeter

$$
\begin{array}{ll}
a=4745.53 & X 1_{\lambda}=\text { Band 2 } \\
b=-10968.82 & X 2_{\lambda}=\text { Band 6 } \\
c=-3153.92 & X 3_{\lambda}=\text { Band 7 }
\end{array}
$$

$d=4966.71$

Dissolved oxygen (DO) model

$$
\mathrm{DO}_{\mathrm{mg} / \mathrm{L}}=a+\left(X 1_{\lambda} \times b\right)+\left(X 2_{\lambda} \times c\right)+\left(X 3_{\lambda} \times d\right)
$$

where DO is in milligram per liter

$$
\begin{aligned}
& a=9.679 \\
& b=-3.038 \\
& c=-4.793 \\
& d=0.752
\end{aligned}
$$$$
X 1_{\lambda}=\text { Band 6/Band } 8
$$$$
X 2_{\lambda}=\text { Band } 4-\text { Band } 7 / \text { Band } 4+\text { Band } 8
$$

Water depth model$$
X 3_{\lambda}=\text { Band 4/Band } 8
$$

$$
\text { Depth }_{\text {meter }}=a+\left(X 1_{\lambda} \times b\right)+\left(X 2_{\lambda} \times c\right)+\left(X 3_{\lambda} \times d\right)
$$


Table 2. Correlation matrix between the environmental variables and the WV-2 data.

\begin{tabular}{|c|c|c|c|c|c|c|c|c|c|c|c|}
\hline $\begin{array}{c}\text { Band } \\
\text { selection }\end{array}$ & EC & TDS & $\mathrm{pH}$ & DO & Depth & $\begin{array}{c}\text { Band } \\
\text { selection }\end{array}$ & EC & TDS & $\mathrm{pH}$ & DO & Depth \\
\hline Band 1 & -0.307 & -0.345 & -0.063 & 0.144 & -0.213 & B1/B2 & $0.435^{*}$ & 0.348 & 0.142 & -0.204 & $0.622^{* *}$ \\
\hline Band 2 & $-0.668^{* *}$ & $-0.611^{* *}$ & -0.188 & 0.286 & $-0.628^{* *}$ & B1/B3 & 0.210 & 0.105 & 0.335 & $-0.403^{*}$ & $0.594^{* *}$ \\
\hline Band 3 & $-0.376^{*}$ & -0.314 & -0.326 & $0.417^{*}$ & $-0.595^{* *}$ & B1/B4 & 0.275 & 0.188 & 0.092 & -0.107 & $0.848^{* *}$ \\
\hline Bnad 4 & $-0.382^{*}$ & -0.321 & -0.106 & 0.143 & $-0.780^{* *}$ & B1/B5 & 0.212 & 0.183 & 0.130 & -0.292 & $0.718^{* *}$ \\
\hline Band 5 & -0.299 & -0.293 & -0.142 & 0.295 & $-0.661^{* *}$ & B1/B6 & $0.385^{*}$ & $0.367^{*}$ & 0.071 & $-0.361^{*}$ & $0.702^{* *}$ \\
\hline Band 6 & $-0.445^{*}$ & $-0.434^{*}$ & -0.049 & 0.316 & $-0.629^{* *}$ & B2/B3 & -0.255 & -0.263 & 0.188 & -0.218 & 0.118 \\
\hline Band 8 & -0.277 & -0.239 & -0.171 & $0.504^{*}$ & $-0.601^{* *}$ & B2/B5 & -0.035 & -0.016 & 0.056 & -0.207 & $0.514^{*}$ \\
\hline B7/B8 & -0.056 & -0.066 & 0.050 & $-0.426^{*}$ & 0.223 & B2/B6 & 0.309 & 0.312 & 0.039 & -0.339 & $0.623^{* *}$ \\
\hline B6/B8 & 0.065 & 0.027 & 0.195 & $-0.571^{* *}$ & $0.408^{*}$ & B2/B7 & 0.317 & 0.282 & 0.163 & $-0.397^{*}$ & $0.661^{* *}$ \\
\hline B6/B7 & 0.181 & 0.129 & 0.242 & -0.281 & $0.360^{*}$ & B2/B8 & 0.208 & 0.181 & 0.149 & $-0.559^{* *}$ & $0.628^{* * *}$ \\
\hline B5/B8 & 0.231 & 0.199 & 0.152 & $-0.557^{* *}$ & $0.541^{*}$ & WVIND1 & 0.013 & 0.013 & 0.195 & $-0.548^{*}$ & $0.395^{*}$ \\
\hline B5/B7 & $0.354^{*}$ & 0.316 & 0.147 & $-0.361^{*}$ & $0.539^{*}$ & WVIND2 & -0.037 & -0.014 & 0.061 & -0.209 & $0.511^{*}$ \\
\hline B5/B6 & $0.378^{*}$ & $0.372^{*}$ & 0.006 & -0.281 & $0.460^{*}$ & WVIND3 & 0.200 & 0.167 & -0.135 & 0.176 & $0.595^{* *}$ \\
\hline B4/B7 & $0.360^{*}$ & 0.330 & 0.173 & $-0.453^{*}$ & $0.555^{* *}$ & WVIND5 & 0.379 & $0.360^{*}$ & 0.188 & $-0.467^{*}$ & $0.529^{*}$ \\
\hline B4/B6 & $0.372^{*}$ & $0.389^{*}$ & 0.036 & $-0.403^{*}$ & $0.465^{*}$ & WVIND6 & -0.057 & 0.008 & 0.066 & -0.269 & -0.036 \\
\hline B4/B5 & -0.054 & 0.006 & 0.065 & -0.271 & -0.026 & WVIND7 & 0.013 & -0.025 & 0.007 & 0.021 & $0.697^{* *}$ \\
\hline B3/B8 & 0.238 & 0.212 & 0.130 & $-0.533^{*}$ & $0.617^{* *}$ & WVIND8 & 0.207 & 0.102 & 0.340 & $-0.408^{*}$ & $0.593^{* *}$ \\
\hline B3/B7 & 0.349 & 0.318 & 0.126 & -0.346 & $0.632^{* *}$ & WVIND9 & -0.248 & -0.258 & 0.188 & -0.217 & 0.124 \\
\hline B3/B6 & $0.365^{*}$ & $0.370^{*}$ & -0.010 & -0.275 & $0.594^{* *}$ & WVIND10 & -0.061 & -0.077 & 0.058 & $-0.414^{*}$ & 0.219 \\
\hline B3/B5 & 0.108 & 0.134 & -0.049 & -0.091 & $0.442^{*}$ & WVIND11 & 0.224 & 0.185 & 0.149 & $-0.523^{*}$ & $0.510^{*}$ \\
\hline B3/B4 & 0.189 & 0.157 & -0.131 & 0.172 & $0.599^{* *}$ & WVIND12 & $0.381^{*}$ & 0.342 & 0.160 & $-0.373^{*}$ & $0.519^{*}$ \\
\hline \multicolumn{2}{|c|}{ Index } & \multicolumn{2}{|c|}{ Description } & \multicolumn{2}{|c|}{ Index } & \multicolumn{2}{|c|}{ Description } & \multicolumn{2}{|c|}{ Index } & \multicolumn{2}{|c|}{ Description } \\
\hline \multicolumn{2}{|c|}{ WVIND1 } & \multicolumn{2}{|c|}{$\mathrm{B} 6-\mathrm{B} 8 / \mathrm{B} 6+8$} & \multicolumn{2}{|c|}{ WVIND5 } & \multicolumn{2}{|c|}{$\mathrm{B} 4-\mathrm{B} 7 / \mathrm{B} 4+7$} & \multicolumn{2}{|c|}{ WVIND9 } & \multicolumn{2}{|c|}{$\mathrm{B} 2-\mathrm{B} 3 / \mathrm{B} 2+\mathrm{B} 3$} \\
\hline \multicolumn{2}{|c|}{ WVIND2 } & \multicolumn{2}{|c|}{$\mathrm{B} 2-\mathrm{B} 5 / \mathrm{B} 2+\mathrm{B} 5$} & \multicolumn{2}{|c|}{ WVIND6 } & \multicolumn{2}{|c|}{$\mathrm{B} 4-\mathrm{B} 5 / \mathrm{B} 4+\mathrm{B} 5$} & \multicolumn{2}{|c|}{ WVIND10 } & \multicolumn{2}{|c|}{$\mathrm{B} 7-\mathrm{B} 8 / \mathrm{B} 7+\mathrm{B} 8$} \\
\hline \multicolumn{2}{|c|}{ WVIND3 } & \multicolumn{2}{|c|}{$\mathrm{B} 3-\mathrm{B} 4 / \mathrm{B} 3+\mathrm{B} 4$} & \multicolumn{2}{|c|}{ WVIND7 } & \multicolumn{2}{|c|}{$\mathrm{B} 2-\mathrm{B} 4 / \mathrm{B} 2+\mathrm{B} 4$} & \multicolumn{2}{|c|}{ WVIND11 } & \multicolumn{2}{|c|}{$\mathrm{B} 5-\mathrm{B} 8 / \mathrm{B} 5+\mathrm{B} 8$} \\
\hline \multicolumn{2}{|c|}{ WVIND4 } & \multicolumn{2}{|c|}{$\mathrm{B} 4-\mathrm{B} 8 / \mathrm{B} 4-\mathrm{B} 8$} & \multicolumn{2}{|c|}{ WVIND8 } & \multicolumn{2}{|c|}{$\mathrm{B} 1-\mathrm{B} 3 / \mathrm{B} 1+\mathrm{B} 3$} & \multicolumn{2}{|c|}{ WVIND12 } & $\mathrm{B} 5-\mathrm{B} 7$ & $5+B 7$ \\
\hline
\end{tabular}

Note: Correlation is significant at the ${ }^{*} \mathrm{P}<0.05$ level and ${ }^{* *} \mathrm{P}<0.01$ level (2-tailed). 

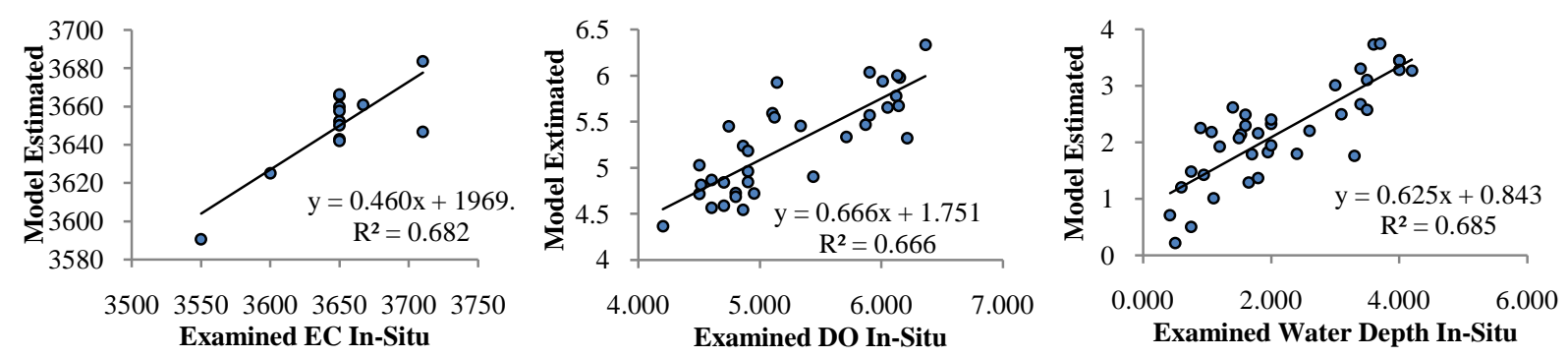

Figure 3. Linear correlation coefficient between examined parameters with model estimated values.

where DO is in milligram per liter

$$
\begin{array}{ll}
a=4.303 & X 1_{\lambda}=\text { Band 1/Band } 5 \\
b=3.275 & X 2_{\lambda}=\text { Band 1/Band } 4 \\
c=0.45 & X 3_{\lambda}=\text { Band } 4 \\
d=-145.282 &
\end{array}
$$

The cartographic maps for the distribution of electrical conductivity, dissolved oxygen (DO), water depth, based on above mentioned models are shown in Figure 4. Figure 4 shows the spatial distribution of electrical conductivity derived from satellite image (worldview-2). It shows that in the central part of the lake area having high concentration of EC due to high salt content, whereas the shallow areas show the lower electrical conductivity. From the Figure 4 it is inferred that the high DO is found over the shallow area of lake whereas the lower DO is found at the higher depth. The overall the concentration is found in between $4 \mathrm{mg} / \mathrm{L} \mathrm{to} 5 \mathrm{mg} / \mathrm{L}$. From the field survey it is noticed that the correlation with vegetation (Hydrophytic vegetation) is high at the shallow depth around the lake area. Derived DO from satellite image and in-situ observation are very much coincide each other. Figure 4 shows the morphometry of the lake derived from the worldview-2 satellite data. It is inferred from the figure the higher depth are located in the central and western part of the lake area ranges from 3 meter to 6 meters.

\section{Conclusions}

The environmental conditions of any lake system depend upon the nature of that lake and its exposure to various environmental factors. However by increasing urban development and anthropogenic activities, the quality of water has decreased dramatically. Hence, the monitoring program using remote sensing and GIS techniques which are needed to assess all contamination occurs and provides the effective action at all levels. The results indicate that optical remote sensing of bathymetry and geochemical investigation is not only feasible but higher accurate under conditions of typical lake water, supporting field survey. In this paper, we have more closely examined the empirical basis for spectrally based depth retrieval and some geochemical properties. Depths and some geochemical properties estimated from band ratios are most reliable when the remotely sensed signal is comprised primarily of bottom reflected radiance. Since the radiometric quantities involved depend on wavelength, these conditions might hold for some portions of the spectrum but not for others. To examine these spectral variations, band ratio analysis procedure is developed, for identifying pairs of wavelengths that produce strong linear correlation coefficient between the band ratio (Equations (11)-(13)). The Pearson correlation matrix $(\mathrm{R})$ between the examined water samples/depth and the TOA reflectance values of the worldview-2 (WV-2) satellite data have been investigated. Electrical conductivity is highly negatively correlated with Band $2(\mathrm{R}=$ $-0.668)$ whereas with Band $6(\mathrm{R}=-0.445)$ and Band $7(\mathrm{R}=-0.455)$; it shows moderate negative correlation. Dissolved oxygen (DO) is having highly negative correlation with Band 4/Band 8, Band 6/Band 8 and WVIND4 of $\mathrm{R}$ value $-0.602,-0.571$ and -0.579 respectively at the significant level $\mathrm{P}<0.001$ (2-tailed). Water depth is highly correlated with Band 1/Band $4(\mathrm{R}=0.848)$, Band $4(\mathrm{R}=-0.780)$, Band $1 /$ Band $5(\mathrm{R}=0.715)$ and Band 1/Band $6(\mathrm{R}=0.702)$ at the significant level $\mathrm{P}<0.001$ (2-tailed).

The $\mathrm{pH}$ value for the lake water ranges from 7.7 to 8.1. A desirable range of $\mathrm{pH}$ for aquatic life is 6.5 to 9.0. The $\mathrm{pH}$ above or below this threshold value might interfere with reproduction, respiration and other biological functions of aquatic life. DO of the lake water was in the range of $4.38-6.73 \mathrm{mg} / \mathrm{L}$ with the mean of $5.38 \mathrm{mg} / \mathrm{L}$. The available data indicated that Lake Al-Saad water is slight lower than the permissible limit of Saudi standards for lake water $(10 \mathrm{mg} / \mathrm{L})$. The DO in an aquatic ecosystem is responsible for various biochemical 

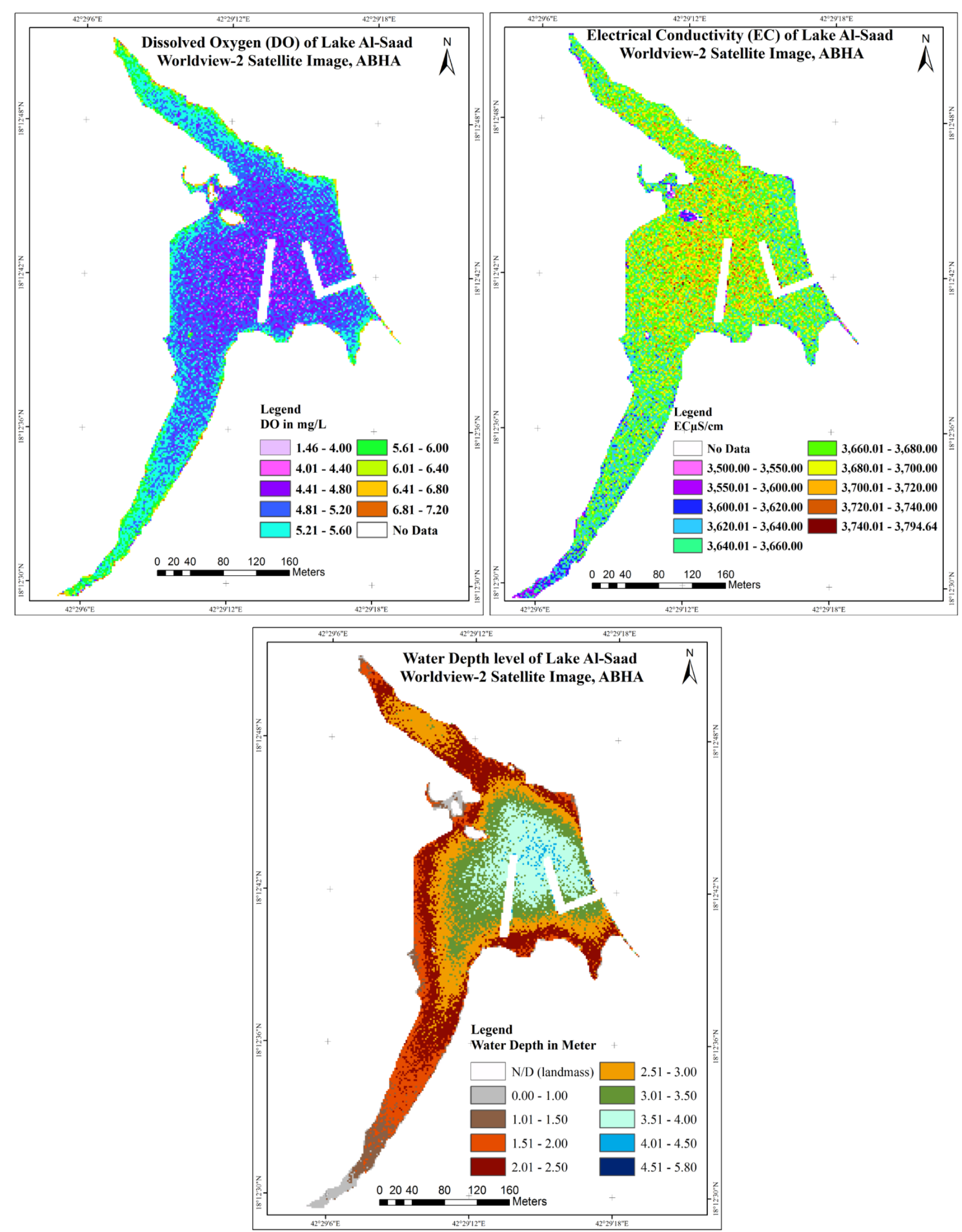

Figure 4. Spatial distribution and histogram of DO, EC and water depth extracted from WV-2 data. 
changes and subsequently its effect on metabolic activities of organisms within the lake ecosystem. In the study area it is found that the shallow water has high DO concentration, whereas the deeper shows significantly lower down. Electrical conductivity measurements serve as a useful indicator of the degree of mineralization in the water sample. All the samples which have EC exceed limit and it ranges from $3366 \mu \mathrm{s} / \mathrm{cm}$ to $3710 \mu \mathrm{s} / \mathrm{cm}$ with the mean value of $3637.79 \mu \mathrm{s} / \mathrm{cm}$. EC of most natural water generally ranges about 50 to $1500 \mu \mathrm{s} / \mathrm{cm}$. In general, with increase of EC, the corrosive nature of the water increases. Figure 3 shows the spatial distribution of EC and TDS, it inferred that the EC and TDS concentration is the highest at the eastern part of the lake whereas concentration drops down towards the southern side.

\section{Acknowledgements}

The author (Dr. Javed Mallick) wish to acknowledge the financial support by Deanship of Scientific Research, King Khalid University, KSA; Project code 74/2012-13.

\section{References}

[1] Liu, Y., Anisul, I.M. and Jay, Gao, J. (2003) Quantification of Shallow Water Quality Parameters. Progress in Physical Geography, 27, 24-43.

[2] Li, W., Hu, P., Xiao, D. and Liu, C. (2004) The Application of the Multi-Beam Sounding to the Marine Engineering Exploration. Geophysical \& Geochemical Exploration, 28, 373-376.

[3] Lyzenga, D.R. (1978) Passive Remote Sensing Techniques for Mapping Water Depth and Bottom Features. Applied Optics, 17, 379-383.

[4] Philpot, W.D. (1989) Bathymetric Mapping with Passive Multispectral Imagery. Applied Optics, 28, 1569-1579.

[5] Lee, Z., Carder, K.L., Mobley, C.D., Steward, R.G. and Patch, J.S. (1999) Hyper-Spectral Remote Sensing for Shallow Waters: Deriving Bottom Depths and Water Properties by Optimization. Applied Optics, 38, 3831-3843.

[6] Stumpf, R.P. and Holderied, K. (2003) Determination of Water Depth with High-Resolution Satellite Imagery over Variable Bottom Types. Limnology and Oceanography, 48, 547-556.

[7] Lesser, M.P. and Mobley, C.D. (2007) Bathymetry, Water Optical Properties, and Benthic Classification of Coral Reefs Using Hyper-Spectral Remote Sensing Imagery. Coral Reefs, 26, 819-829. http://dx.doi.org/10.1007/s00338-007-0271-5

[8] Singh, C.K., Kumari, R., Singh, N., Mallick, J. and Mukherjee, S. (2012) Fluoride Enrichment in Aquifers of Thar Desert: Controlling Factors and Its Geochemical Modeling. Hydrological Processes, John Wiley \& Sons, Ltd., Hoboken. http://dx.doi.org/10.1002/hyp.9245

[9] Jennifer, P.C. and Kendall, L.C. (2006) Estimating Chlorophyll a Concentrations from Remote-Sensing Reflectance in Optically Shallow Waters. Remote Sensing of Environment, 101, 13-24.

[10] Seelig, H.D. Hoehn, A., Stodieck, L.S., Klaus, D.M., Adams, W.W. and Emery, W.J. (2008) Relations of Remote Sensing Leaf Water Indices to Leaf Water Thickness in Cowpea, Bean, and Sugar Beet Plants. Remote Sensing of Environment, 112, 445-455.

[11] Wang, Y., Dong, W. and Zhang, P. (2007) Progress in Water Depth Mapping from Visible Remote Sensing Data. Marine Science Bulletin, 26, 92-101.

[12] Lyzenga, D.R. (1979) Shallow-Water Reflectance Modeling with Applications to Remote Sensing of Ocean Floor. Proceedings of the 13th International Symposium on Remote Sensing of Environment, 1, 583-602.

[13] Polcyn, F.C. and Lyzenga, D.R. (1973) Calculation of Water Depth from ERTS-MSS Data. Symposium on Significant Results Obtained from ERTS-1, NASA Specification Publication, 1433-1436.

[14] Brown, W.L., Polcyn, F.C. and Stewart, S.R. (1971) A Method for Calculating Water Depth, Attenuation Coefficients, and Bottom Reflectance Characteristics in Proceedings. 7th International Symposium on Remote Sensing of the Environment, Ann Arbor, May 1971, 663-680.

[15] Mallick, J., Alashker, Y., Al-Deen Mohammad, S., Ahmed, M. and Hasan, M.A. (2014) Risk Assessment of Soil Erosion in Semi-Arid Mountainous Watershed in Saudi Arabia by RUSLE Model Coupled with Remote Sensing and GIS. Geocarto International, 29, 915-940. http://dx.doi.org/10.1080/10106049.2013.868044

[16] Digital Globe (2010) Radiometric Use of Worldview-2 Imagery. Technical Note.

[17] Gordon, H.R. (1997) Atmospheric Correction of Ocean Color Imagery in the Earth Observing System Era. Journal of Geophysical Research-Atmospheres, 102, 17081-17106

[18] Gordon, H.R., Brown, O.B., Evans, R.H., Brown, J.W., Smith, R.C., Baker, K.S. and Clark, D.K. (1988) A Semi Ana- 
lytic Radiance Model of Ocean Color. Journal of Geophysical Research-Atmospheres, 93, 10909-10924. http://dx.doi.org/10.1029/JD093iD09p10909

[19] Mobley, C.D. (1994) Light and Water: Radiative Transfer in Natural Waters. Academic, San Diego.

[20] Hansen, J.E. and Traves, L.D. (1974) Light Scattering in Planetary Atmospheres. Space Sciences Reviews, 16, 527-610. http://dx.doi.org/10.1007/BF00168069

[21] Voillier, M., Tanré, D. and Deschamps, P.Y. (1980) An Algorithm for Remote Sensing of Water Color from Space. Boundary Layer. Boundary-Layer Meteorology, 18, 247-267. http://dx.doi.org/10.1007/BF00122023

[22] Neckel, H. and Labs, D. (1981) Improved Data for Solar Spectral Irradiance from 0.33 to 1.25 Micrometers. Solar Physics, 74, 231-249. http://dx.doi.org/10.1007/BF00151293

[23] Marsaglia, G., Tsand, W.W. and Wang, J. (2003) Evaluating Kolmogorov’s Distribution. Journal of Statistical Software, 8, 1-4.

[24] Yalouris, K.P., Kollias, V., Lorentzos, N.A., Kalivas, D. and Sideridis, A.B. (1997) An Integrated Expert Geographical Information System for Soil Suitability and Soil Evaluation. Journal of Geographical Information Decision Analysis, 1, 90-100.

[25] Castrignano, A., Cherubini, C., GaisiConsetta, I., Musci, F. and Pastore, N. (2007) Multivariate Geostatistical and Natural Attenuation Model Approach for Remediation of Chlorinated Compounds. WSEAS Transactions on Environment and Development, 3, 90-98.

[26] Klein, L. (1973) River Pollution-Causes and Effects, Vol. 2. Butterworth and Co. Ltd., London.

[27] Chin, D.A. (2000) Water-Resources Engineering. Prentice-Hall Inc., Upper Saddle River, 585-635.

[28] Friedl, G., Teodoru, C. and Wehrli, B. (2004) Is the Iron Gate Reservoir on the Danube River a Sink for Dissolved Silica? Biogeochemistry, 68, 21-32.

[29] Goel, P.K., Gopal, B. and Trivedi, R. (1980) Impact of Sewage on Freshwater Ecosystems. II. Physicochemical Characteristics of Water and Their Seasonal Changes. International Journal of Ecology and Environmental Sciences, 6, 97-116. 
Scientific Research Publishing (SCIRP) is one of the largest Open Access journal publishers. It is currently publishing more than 200 open access, online, peer-reviewed journals covering a wide range of academic disciplines. SCIRP serves the worldwide academic communities and contributes to the progress and application of science with its publication.

Other selected journals from SCIRP are listed as below. Submit your manuscript to us via either submit@scirp.org or Online Submission Portal.
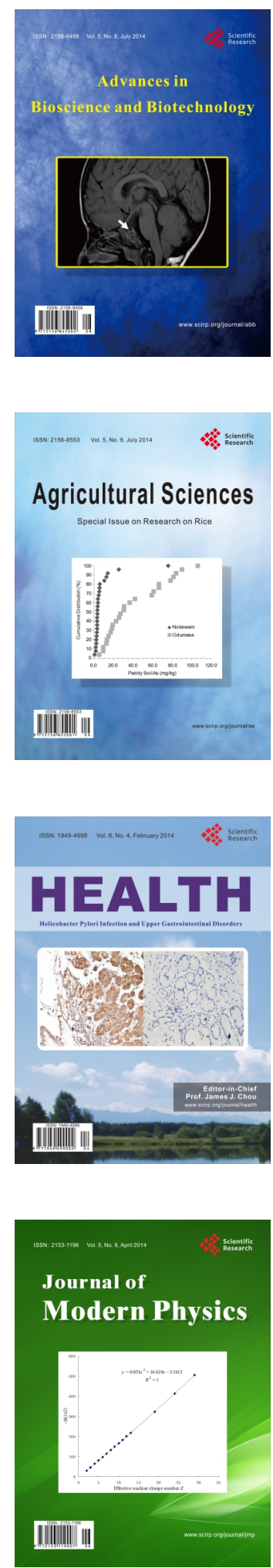
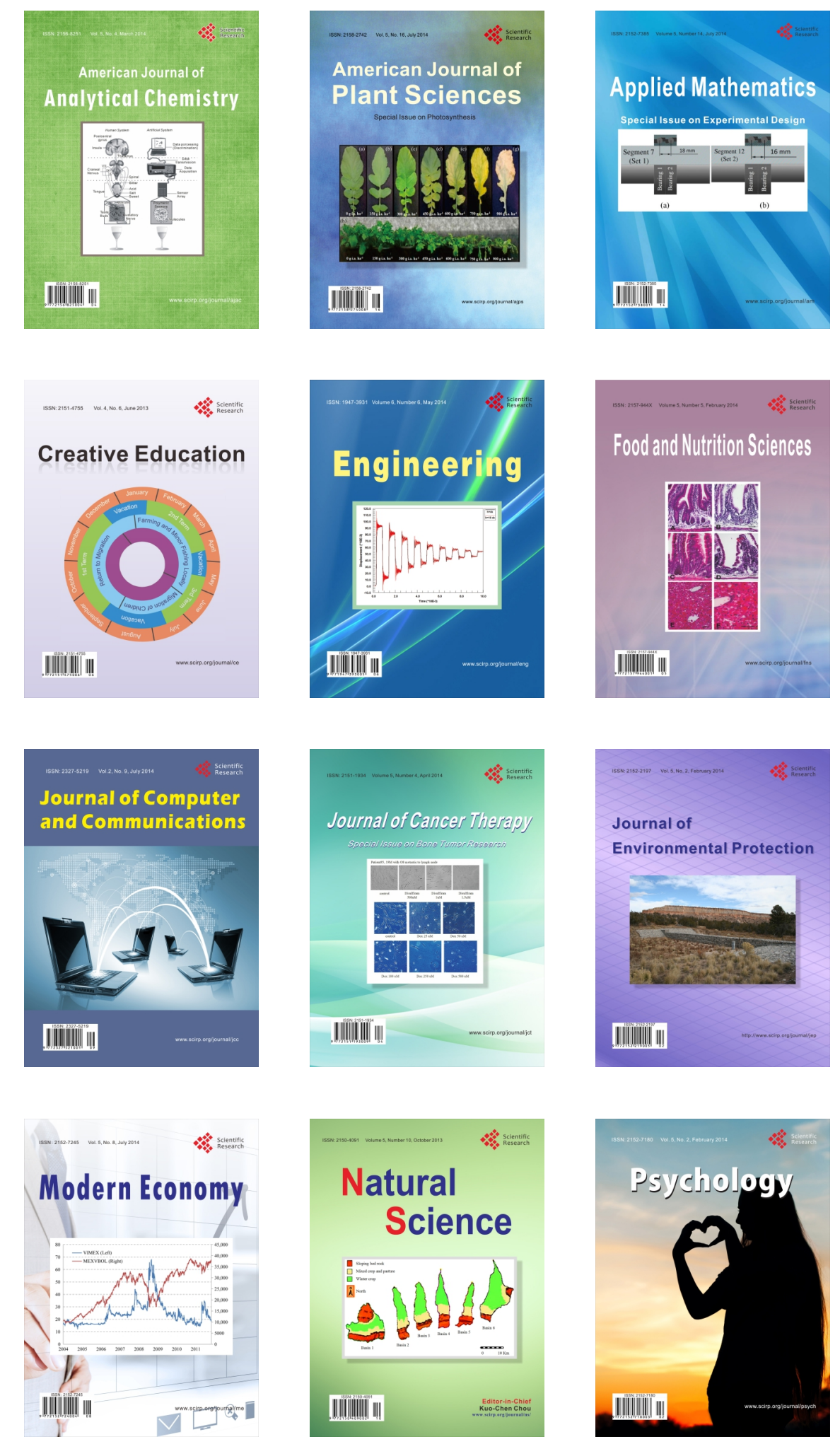